\title{
LIVE STOCK POLICY DURING WAR-TIME
}

\author{
By Dr. Charles Crowther, \\ Principal of the Harper Adams Agricultural College
}

$\mathrm{S}^{\mathrm{IN}}$ NCE the eighties of last century, the main effort of British agriculture has been steadily and increasingly diverted from crop growing to the production of live stock and live stock products. According to recent statistics these now account for about two thirds of the total value of the agricultural output of England and Wales, and an even higher fraction of the Scottish output. This expansion of live stock production with a dwindling arable acreage has only been made possible by the import of feeding-stuffs, which has shown a corresponding rise to a level in recent years of about $7 \frac{3}{4}$ million tons per annum. This represents, according to Wright's estimates, in terms of 'starch equivalent' about 22 per cent of the total nutrients consumed by live stock in a normal year (1935), the balance of 78 per cent being obtained from home-produced fodders, roots and corn. In these terms of gross supply, the proportion of imports does not appear to be unreasonable ; but in terms of concentrated foods the balance assumes a very different aspect, since imports are entirely of this class and amount to more than twice the home-grown supply of concentrates. It is inevitable, therefore, that in times of crisis involving shipping difficulties the supply of imported feeding-stuffs, unless vast reserves have previously been accumulated, must rapidly become a serious problem for the live-stock industry, compelling some change of policy, more or less drastic, for the early stages, if not for the whole period, of the crisis.

The general lines along which such adaptation must take place were evolved by force of circumstances during the War of 1914-1918 : increase of home production of arable crops, utilization of household and other food waste, and rationing of available concentrated feeding-stuffs with priority to those classes of animals which either make more economical use of these concentrates or give a product that is of special importance in the national dietary. In the present emergency, therefore, it has been possible from the outset to formulate the war-time policy for the production of live stock and live stock products along these lines, and with varying degrees of grace the broad principle of the policy appears to have been accepted by the industry.

The necessity for the 'speed the plough' and 'dig for victory' campaigns in the interests of the human consumer are obvious; but both may also be made to contribute substantially to the home supplies of food for live stock, the former through the farm, and the latter through allotments and gardens. A parallel increase must also be effected on our grasslands, where modern research has greatly extended the possibilities of improved management and utilization, and of conservation of surplus produce for winter use. No great expansion of the artificial drying of grass by private enterprise on farms is probable, but serious consideration should be given at once to the possibility of establishing a national grass-drying organization, for which a large nucleus of raw material would be available on aerodromes and other large areas from which the grass needs to be cut and removed periodically through the growing season.

On the majority of farms a corresponding increase in conserved grass supplies would be more readily effected by ensilage, using improved modern methods, and an intensive propaganda directed towards this end ought to be initiated without delay.

By these two methods of conserving young grass, a very substantial reduction in the requirements of ruminant live stock for concentrated foods could be effected, and substantial help thereby given to the solution of the difficult problem of maintaining an adequate head of our non-ruminant stock.

It is on the latter-the pig and the fowl-that the penalty of depleted supplies of concentrates must necessarily fall most heavily, since they can only utilize coarse fodders to a very limited extent, not even sufficient to cover their maintenance requirements, and consequently must depend for the most part upon supplies of grain and meals. According to Wright's estimates of the normal requirements of these classes of live stock under prevailing systems of management, poultry receive 94 per cent, and pigs no less than 97 per cent, of their nutrients (expressed as starch equivalent) in the form of cereals and other concentrates. When these proportions are compared with the corresponding 15-20 per cent for cattle and sheep, and account taken of the paramount importance of maintaining an adequate supply of milk, it is clear that even with drastic changes in systems of management and feeding it will be practically impossible to prevent a considerable fall in the numbers of pigs and poultry. A considerable reduction in the output of pig meat, poultry meat 
and eggs from the normal sources of home supply can thus scarcely be avoided, although since the best stocks will be retained the fall in output from these sources will not be proportional to the drop in numbers. Greater recourse will also be made by pig and poultry farmers to the feeding of food refuse from hotels and camps, and of grassland and surplus greenstufis. So far as the use of grass and greenstuff is concerned, however, it is one of the ironies of the situation that the main responsibility for this task of replacing concentrates by greenstuffs should fall upon the two classes of live stock that are least fitted for dealing with large quantities of this bulky, fibrous type of food.

If home supplies of eggs, poultry meat, and pig meat are to be substantially maintained, a new body of producers must be brought into existence, and that is the task now allotted to the cottager, 'back-yarder', and allotment holder. Every household and every vegetable garden produces a certain amount of waste, useless in the house but serviceable as food for small live stock. Such material is generally more easily and completely disposed of through the pig than the fowl, but for most people, especially in suburban areas, pigkeeping will be impossible, and the effort must be concentrated on fowls and rabbits. War-time economy, moreover, will surely reduce the normal volume of household 'scraps' available, and the keeping of even a few fowls or rabbits will only be possible where an organized collection of the scraps from several households can be arranged. In a community properly organized for the purpose, the best plan of all would be for the edible refuse of all kinds to be collected and taken to a communal live stock feeding centre where expert management and proper facilities for the preparation of the food could be provided. Such a centre, with good management, might well be a substantial source of profit to the community.

Before taking up poultry keeping, the 'backyarder' will be well advised to bear in mind that his household scraps and garden refuse alone will not suffice to maintain his birds in good health and production; but that he will also need to obtain a quantity of suitable meal, probably at least $\frac{3}{4}-1 \mathrm{lb}$. per head weekly. Furthermore he must be prepared to go to a little trouble in boiling or cooking the scraps, as they may be unsuitable or even unsafe in the raw condition. Where garden waste is more abundant than house scraps he would probably be better advised to keep rabbits than poultry, since the rabbit can deal effectively with larger quantities of greenstuffs than the hen, and is generally less fastidious in its appetite for this class of food. Incidentally also, it is perhaps less liable to create a nuisance. German war-time policy for the 'back-yarder' definitely favours the rabbit before the hen, and its possibilities might well receive more attention and publicity in Great Britain than they have yet received.

Whatever class of live stock is favoured, however, it must not be assumed to be a simple matter on which no expert advice is required, and every community in which this class of activity develops should provide an organization through which such help can be readily obtained. There should be no difficulty in any town in forming an advisory panel of experienced men and women, with whom might be associated the adviser on small live stock from the agricultural educational staff of the adjoining county authority. Further assistance is also available in the special leaflets issued by the Ministry of Agriculture and Fisheries.

With all the assistance that may come from the cottager and 'back-yarder', however, the major part of the problem of conserving the greatest possible nucleus of our live stock must lie with the farmer, and must turn upon the efficiency with which our grassland and our reduced supplies of concentrated foods are utilized. There is general agreement that in the interests of children and others for whom milk is almost a vital necessity, and in view of our entire dependence upon home supplies of this commodity, priority in the allocation of feeding-stuffs must be given to milch cows. Beef cattle and sheep are regarded as having the next best claim to consideration, partly because of their relatively low requirement of concentrated feeding-stuffs in proportion to their total food consumption, and partly because of the slowness with which any reduction in our cattle and sheep stocks can be remedied after the War. Poultry and pigs follow without any special discrimination between them in the national policy, although the poultryman may justly claim precedence on grounds of the special nutritive virtues of the egg, through its combination of high nutritive energy with 'protective' factors. From this point of view, indeed, the hen may claim to rank next to the dairy cow in the basic importance of its contribution to the national dietary.

Placed at their present disadvantage in the order of priority, the pig farmer and poultry farmer have clearly the right to insist that every care shall be taken to ensure that the more favoured classes of live stock are efficiently managed, especially as regards their user of imported feeding-stuffs. This can only be effected satisfactorily through an organized scheme of rationing of supplies. Under such a scheme the dairyman, cattleman and sheepman should only receive priority supplies for their surplus production beyond the level that they may reasonably be expected to cover from home-grown supplies of fodder and grain. Furthermore, the 
total volume of milk and meat production in respect of which priority of foodstuff supply is given should be restricted to the essential needs of the public. A volume of milk, for example, that is ample for the needs of infants, adolescents, invalids, etc., must be assured at all costs ; but in view of the serious position in which pig and poultry producers are placed, it is difficult to see why any priority should be given for the production of unlimited supplies of milk for consumption by the adult population.

With the increased arable acreage and intensified utilization of grassland the requirements of the ruminant live stock for imported concentrates should be very substantially reduced, and the pigman and poultry-man have every right to expect this measure of co-operation from their more favoured fellow farmers.
In the case of the poultry-man, and to a smaller degree the pig-man, there are also other weighty considerations that must be taken into account in the development of national policy. A very large section of the poultry industry is in the hands of 'small' people scattered throughout the country. side, whose living and life-savings are entirely bound up with the maintenance of their small enterprises. The welfare of this smallholder element of the agricultural community has always been regarded as being of great importance to the interests of the State, and any ill-considered reversal of this policy, even in war-time, may have grave sociological consequences. Their problem is for the time being extremely difficult, but must receive serious consideration before we can resign ourselves to the inevitability of human sacrifice on the home food production front.

\section{CAROTENE AND ALLIED PIGMENTS*}

$\mathrm{T}$ $\mathrm{HE}$ simplest carotenoid is lycopene, $\mathrm{C}_{40} \mathrm{H}_{56}$; on complete hydrogenation to perhydrolycopene, $\mathrm{C}_{40} \mathrm{H}_{82}$, thirteen bonds disappear. Quantitative degradation by means of ozone, permanganate and chromic acid as oxidizing agents leads to the formula:
Green leaves and other vegetable products contain $\alpha$ - and $\beta$-carotene and 'xanthophyll', a mixture of hydroxylated carotenoids, zeaxanthin and lutein predominating. Their functions in plant physiology are not yet understood, but

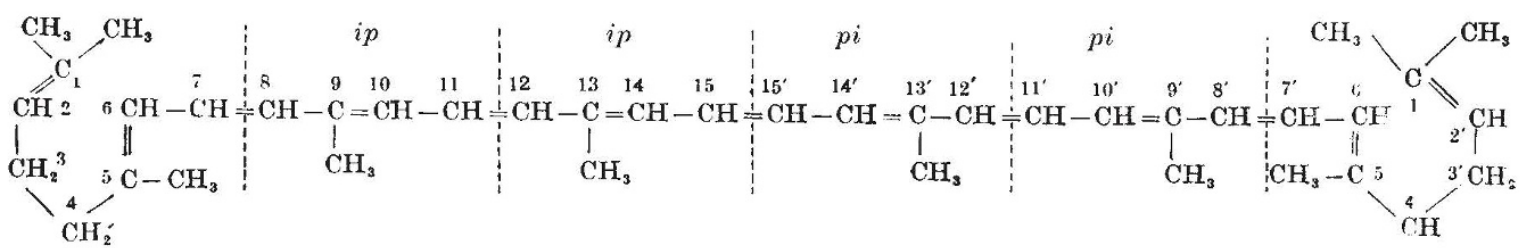

The central polyene chain, $\mathrm{C}_{8}-\mathrm{C}_{8^{\prime}}$ inclusive, is made up of four isoprene units arranged in pairs which are united in reverse order at $\mathrm{C}_{15}$ and $\mathrm{C}_{15}$, and may be abbreviated as ipippipi (ip denoting an isoprene unit). Lycopene may thus be written

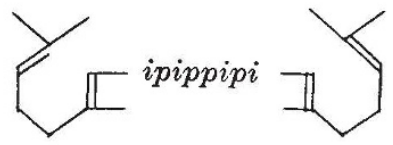

The polyene chain is common to a large number of carotenoids, but the terminal groups may consist of substituted or unsubstituted rings of the $\alpha$ - or $\beta$-ionone type as below : owing to the connexion between carotene and vitamin $\mathrm{A}$, the position concerning the role of carotenoids in the nutrition of animals is much less obscure.

Vitamin A from fish liver oils $\left(\mathrm{C}_{20} \mathrm{H}_{29} \mathrm{OH}\right)$ possesses a constitution which differs from one half of the symmetrical $\beta$-carotene molecule

* Based on papers by Dr. R. A. Morton "On the Constitution and Physiological Significance of Carotene and Allied Pigments", and W. M. Seaber, "On the Commercial Determination of Carotene and Allied Pigments with Special Reference to Dried Grass and other Leafy Materials", read at a joint meeting of the Society of Public Analysts and Other Analytical Chemists and the Food Group of the Society of Chemical Industry on February 7.

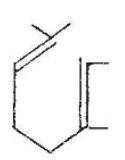

$\boldsymbol{a}$<smiles>CC1=CCCCC1(C)C</smiles>

$b$

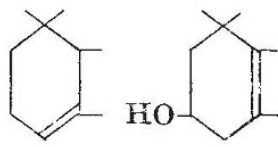

c

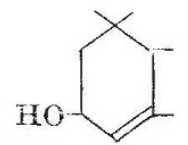

$e$<smiles>CC1=CC(=O)CC(C)(C)C1</smiles>

$f$

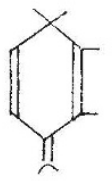

$g$

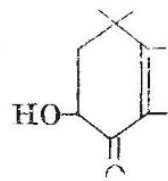

$h$ 